\title{
Identification and Control of Impressed Current Cathodic Protection System
}

\author{
Bassim N. Abdul Sada \\ Electrical Eng. Department, \\ College of Engineering, \\ University of Basrah
}

\author{
Ramzy S. Ali \\ Electrical Eng. Department, \\ College of Engineering, \\ University of Basrah
}

\author{
Khearia A. Mohammed Ali \\ Electrical Eng. Department, \\ College of Engineering, \\ University of Basrah
}

\begin{abstract}
In this paper the identification and control for the impressed current cathodic protection (ICCP) system are present. Firstly, an identification model using an Adaptive Neuro-Fuzzy Inference Systems (ANFIS) was implemented. The identification model consists of four inputs which are the aeration flow rates, the temperature, conductivity, and protection current, and one output that represented by the structure-to-electrolyte potential. The used data taken from an experimental CP system model, type impressed current submerged sample pipe carbon steel. Secondly, two control techniques are used. The first control technique use a conventional Proportional-Integral-Derivative (PID) controller, while the second is the fuzzy controller. The PID controller can be applied to control ICCP system and quite easy to implement. But, it required very fine tuning of its parameters based on the desired value. Furthermore, it needed time response more than fuzzy controller to track reference voltage. So the fuzzy controller has a faster and better response.
\end{abstract}

Index Terms - ANFIS, cathodic protection, Fuzzy Controller, ICCP system, Reference electrode.

\section{INTRODUCTION}

Corrosion is not new topic. It has been around since the beginning of time. Corrosion is the change of a material properties or shape over time due to the environmental effects. It is the natural tendency of a material compositional elements to return to their most thermodynamically stable state. Corrosion is both dangerous and costly. Millions of dollars are spent annually for the repair and replacement of corroded structures such as, tanks, pipelines, and many other items [1]. Among the different corrosion control methods available, Cathodic Protection (CP) is an electrochemical method used to control or prevent corrosion of submerged or buried metallic structures. CP is very simply protection method which is used a current embedded from an external source to inverting the discharge of corrosion current from anodic areas. The most important measurements made in $\mathrm{CP}$ is the structure-to-electrolyte potential via reference electrode (half-cell). It is observe to note that $\mathrm{CP}$ does not prevent corrosion; it oppose corrosion form the protected material surface or structure to the consumable external current source or anode [2]. CP can be operated in either of two methods. Via the use of an impressed current from external electrical source (ICCP), or by using of sacrificial anodes (Galvanic action) (SACP). Each method depends on a number of economic and technical considerations. In the first method, the submerged or buried pipe receives current from a DC power source by an auxiliary inert electrode submerged or buried. The auxiliary electrode becomes as an Anode and the structure to be protected as a cathode. The second method use an active anode which has a negative potential more than the structure wants to be protected and electrically connecting it to form a cell and buried in the Electrolyte. The anode active metal corrodes (sacrificed), whereas the material surface cathode is protected. It is used generally on buried structures, where $\mathrm{CP}$ current requirements are relatively small and where the soil resistivity is low [3].

This field was still an active area for researchers, such as Nagy K. M. developed software package for tanks CP system designed by using MATLAB program to calculate the total current, and the total number of anodes demand. Two methods are suggested for CP system, ICCP, and SACP systems [4]. Balla proposed an Internal Model Control based Proportional Integral Derivative (IMC-PID) controller to control an ICCP system at different operation conditions [5]. Hashim M. S. suggested identification and control for CP system. This work included an experimental and theoretical investigation for a case study of CP system [6]. Sai Shankar 
designed and implemented an ICCP system to eliminated corrosion in underground pipeline which fed power source from a solar energy [7]. Wang $\mathrm{X}$. proposed a remotely controlled ICCP system, via a color touch screen that linked with the ICCP master control panel and serial port [8].

The paper has been structured as follows, section 1 gives a methodology for proposed system. Identification and control are shown in section 2. Section 3 gives the experimental procedure and section 5 will introduces the results and discussions.

\section{METHODOLOGY}

\section{A) Experimental Procedure}

To study the effect of several parameters of ICCP system that used to protect the carbon steel pipe, it is necessary to build a prototype $\mathrm{CP}$ system. Fig. 1 shows the block diagram of the ICCP system. The model consists of the DC power supply, an impressed current graphite anode, corrosive solution, and the working electrode (cathode) to be protected. The power supply drives positive current from the Graphite anode through the saltwater solution and to the working electrode. In order to achieve cathodic protection, the Graphite anode and the carbon steel pipe must both be electrolytic and electrically in contact. Figure 2 shows the experimentally setup of the Installed ICCP system model.

The details description of all parts of the suggested ICCP system is indicated in the following:

- Cathode (working electrode): A carbon steel pipe was used in this study for many reasons: it is widely used in industry especially in the oil field, and its price is relatively low. Furthermore, it provides material properties that are acceptable for such application. Its chemical compositions are $(\mathrm{C}=0.18, \mathrm{P}=0.063, \mathrm{Mn}=0.52, \mathrm{~S}=0.039$, $\mathrm{Si}=0.24, \mathrm{Ni}=0.10, \mathrm{Cu}=0.29, \mathrm{Fe}=$ Remainder $). \mathrm{It}$ is placed horizontally at a depth of $5 \mathrm{~cm}$ below the corrosive solution and $5 \mathrm{~cm}$ above the bottom of the bath. Its dimension is $(10 \mathrm{~cm}$ length, $5.2 \mathrm{~cm}$ inside diameter, $6 \mathrm{~cm}$ outside diameter and $4 \mathrm{~mm}$ wall thickness).

- Anode (auxiliary electrode): A rod made of graphite with dimensions of $(20 \mathrm{~cm}$ length, and 1 $\mathrm{cm}$ diameter) was used. This rod was located horizontally along to the working electrode (cathode) at the same level. The graphite anode is one of the most commonly used for impressed current systems, and was chosen for the following reasons [9]: Low in cost and it is non consumable. Readily available in a variety of size. Environmentally safe, and Graphite anode performance is better in seawater than in fresh water.

- Reference Electrode: the purpose of using reference electrode is to determine the potential between the carbon steel pipe (cathode) and the environment or the surrounding electrolyte. The cathodic potential was measured on saturated calomel electrode (SCE), which is known as the structure-to-electrolyte potential.

- Solution: this is experimentally prepared in different concentrations of sodium chloride $\mathrm{NaCl}$ to the reverse osmosis (R.O) water by adding different weights in order to obtain the corrosive solution with different conductivities as $(0.110$, 16.16 ) $\mathrm{mS} / \mathrm{cm}$, respectively. The $\mathrm{NaCl}$ was a commercial type with purity of about $90 \%$ which is used as corrosive solution.

The experimental procedures dealt with installation of a CP system for a submerged pipe in the reverse osmosis (R.O) water with different conductivities:

1- Using two pipes segment (Cathode) old and new, which are placed in the ICCP system. A couple of copper wires were tied to each clean pipe surface by braze welding. One of these wires was connected to the negative terminal of DC power supply and the other was tied to the reference electrode which was used to measure the cathodic potential.

2- CP system was installed as shown in Figure 2, the reference electrode was mounted at the first edge at the center point of the cathode length. The working and auxiliary electrodes were $40 \mathrm{~cm}$ apart and immersed in the solution at a depth of $5 \mathrm{~cm}$ from the top and the bottom, respectively.

3- Different weights of $\mathrm{NaCl}$ were dissolved in approximately 27 liter of R.O water (represented in the dimensions of a glass bath that used in the experimental setup). The electrolytic solution was stirred by electrical stirrer to obtain a homogenous solution and the temperature of the solution was adjusted and changed in the range $(14-45)^{\circ} \mathrm{C}$ at each run.

4- The aeration flow rate must be changed by using two air pumping device which were placed at the center point of the distance between the anode and cathode. The aeration flow rates employed were adjusted at $(0,600,1500$, and 2100) $1 / \mathrm{h}$. 
5- The electrode potential was measured with respect to saturated calomel electrode using multirange voltmeter. To make the protection value of potential at required level, the voltage of the D.C power supply was changed until the optimum value was obtained. The current was recorded at every change of parameters until the value reached to the steady state i.e. between 800 to 900 $\mathrm{mV}$. This voltage range gives the best results from the range $(800-850) \mathrm{mV}$, because its difficulty to measure the protective current into first range.

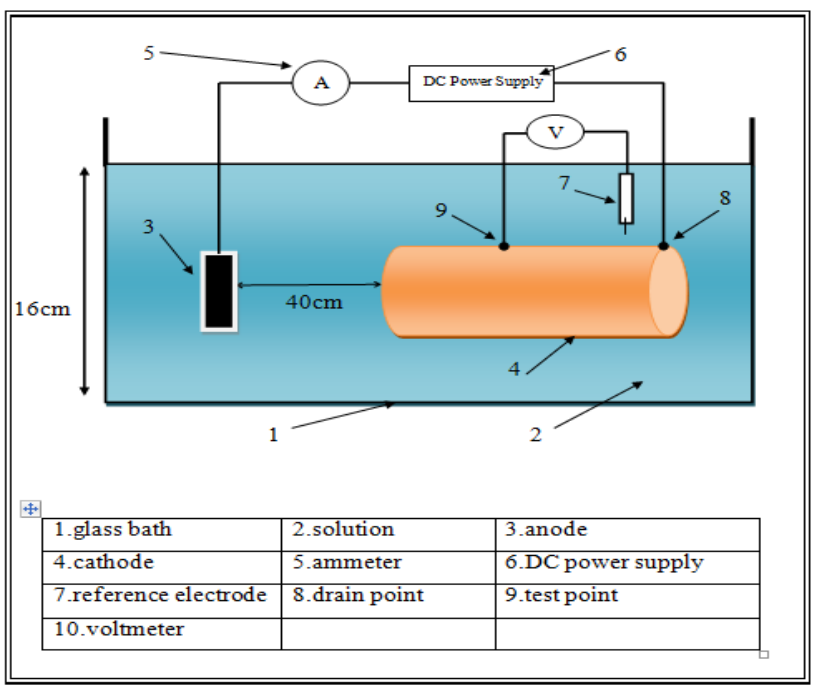

Fig. 1 Block Diagram of the Installed ICCP system.

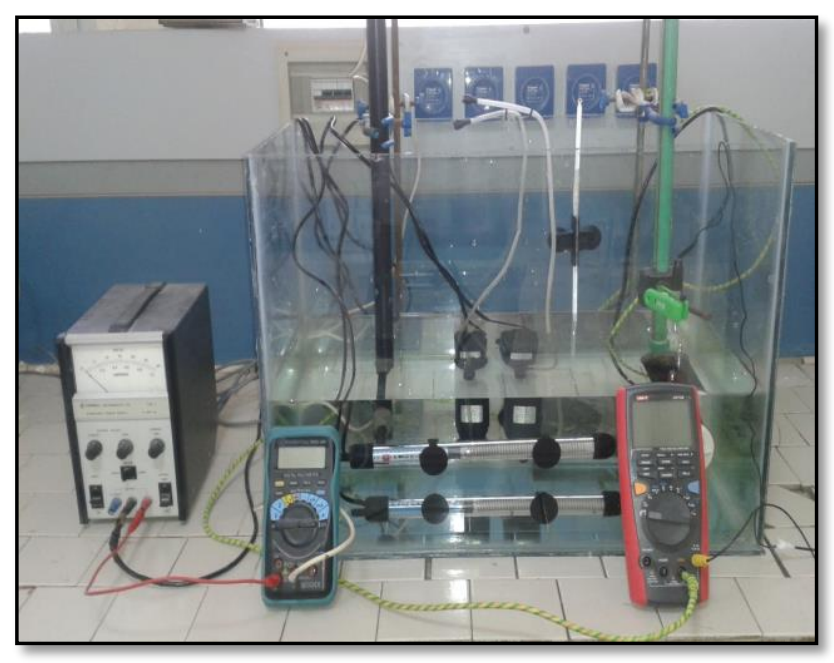

Fig. 2 Photo of the Installed ICCP System.

\section{B) Experimental Results and Discussion}

A series of experiments and data measurement were carried out, that show the effect of changing the parameters like temperature, conductivity, and the aeration flow rate of the corrosive saltwater solution, due to increasing of the cathodic protection current. Figures 3 and 4 show, the change of protective current with temperature at different values of the aeration flow rate of the solution at conductivity value equal to 0.110 $\mathrm{mS} / \mathrm{cm}$ for two segment of pipes. It is clear from figures that the impressed current required for protection was increased for the old and new pipes but have large protective current for the old pipe segment. Figures 5 and 6 show the protective current changes with temperature for different flow rate values at conductivity value equal to $16.16 \mathrm{mS} / \mathrm{cm}$. As a result, the impressed current required for protection more increased with increasing the conductivity and the cathodic protection current required for the old pipe greater than the new pipe segment for protection.

From the experimental results, it can be concluded that:

i) The solution conductivity increased (resistivity decreased) with increasing of salt concentration, the impressed current required for protection is increased.

ii) The temperature is increased by portable water heater, the impressed current required for protection is increased. Due to the change in temperature that cause to increase the ionic mobility of the species which leads to increase the corrosion rate.

iii) The aeration flow rates of the solution increased by air pumping device. This cause the impressed current required for protection to increase. Because of, the increased availability of reducible species at the structure surface, the rate of the cathodic reaction will be increased, i.e. consuming more electrons.

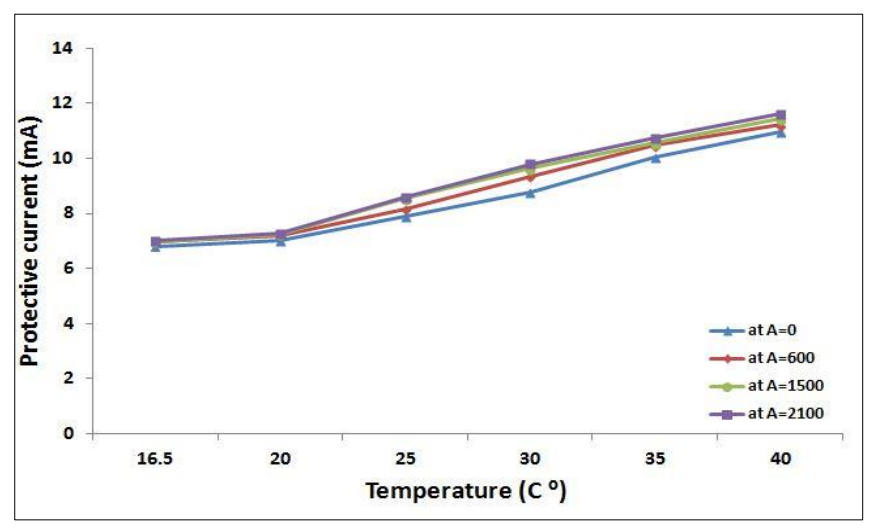

Fig. 3 Protective current vs temperature at 0.110 $(\mathrm{mS} / \mathrm{cm})$ conductivity of the old pipe segment. 


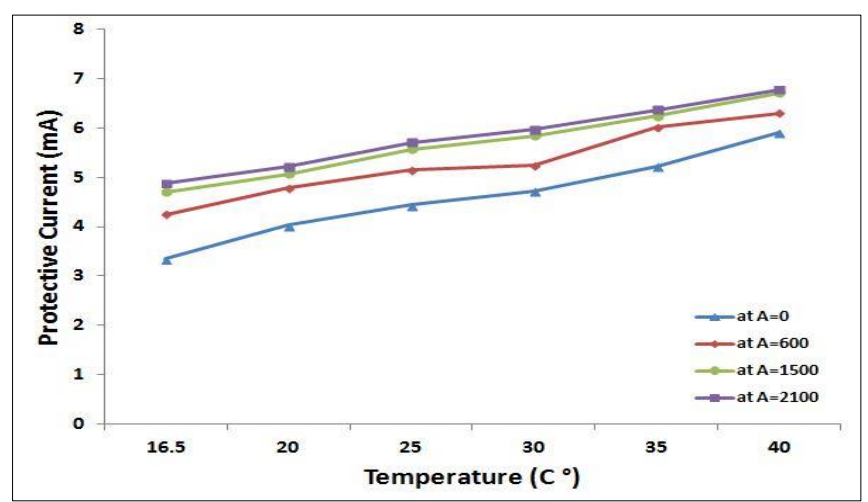

Fig.4 Protective current vs temperature at 0.110 $(\mathrm{mS} / \mathrm{cm})$ conductivity of the new pipe segment.

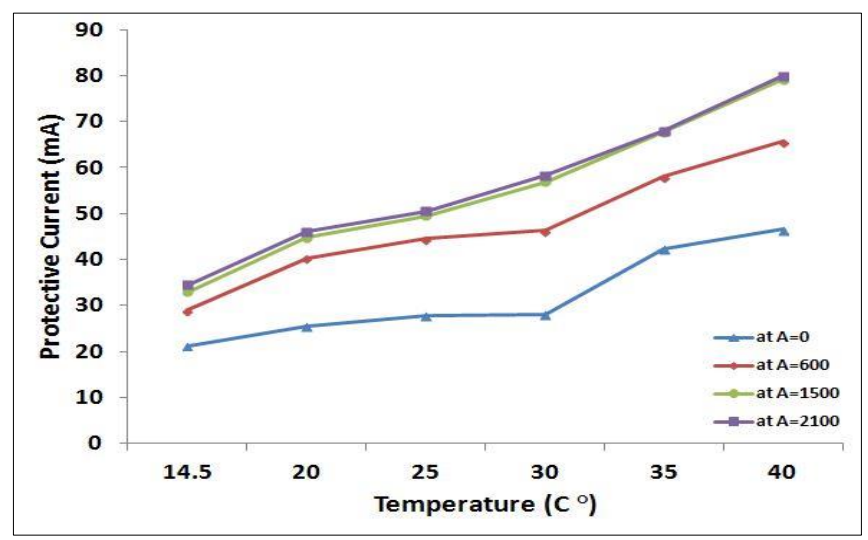

Fig.5 Protective current vs temperature at 16.16 $(\mathrm{mS} / \mathrm{cm})$ conductivity of the old pipe segment.

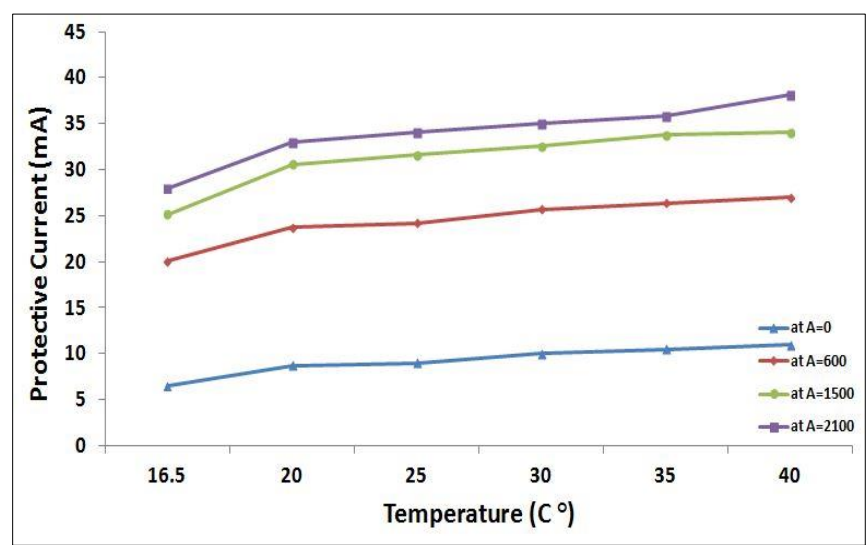

Fig.6 Protective current vs temperature at 16.16 $(\mathrm{mS} / \mathrm{cm})$ conductivity of the new pipe segment.

\section{MODEL IDENTIFICATION AND CONTROL OF ICCP SYSTEM}

This section consists of two parts. The first part represent the model identification of ICCP system by using an Adaptive Neuro-Fuzzy Inference System (ANFIS) technique, and the second part represent its control.

\section{A) Model Identification}

ANFIS is used to identify the model of ICCP system, where the inputs are the aeration flow rates, the temperature, conductivity, and protection current, while the output is the structure-to-electrolyte potential (the structure's voltage). The data is getting from experimental results of the previous section. Figures 7, 8, 9, and 10 show steps and simulation block diagrams of the system identification process using MATLAB program. Figure 7 shows the ANFIS editor windows to load data from file or workspace, generate, and training fuzzy inference system. Figure 8 represents the load data from file to select the type of train, also chosen number and type of membership function. Figure 9 shows the training data and output of FIS at epochs equal to 100 and error tolerance zero. Figure 10 represents the equivalent model of ICCP system by using ANFIS.

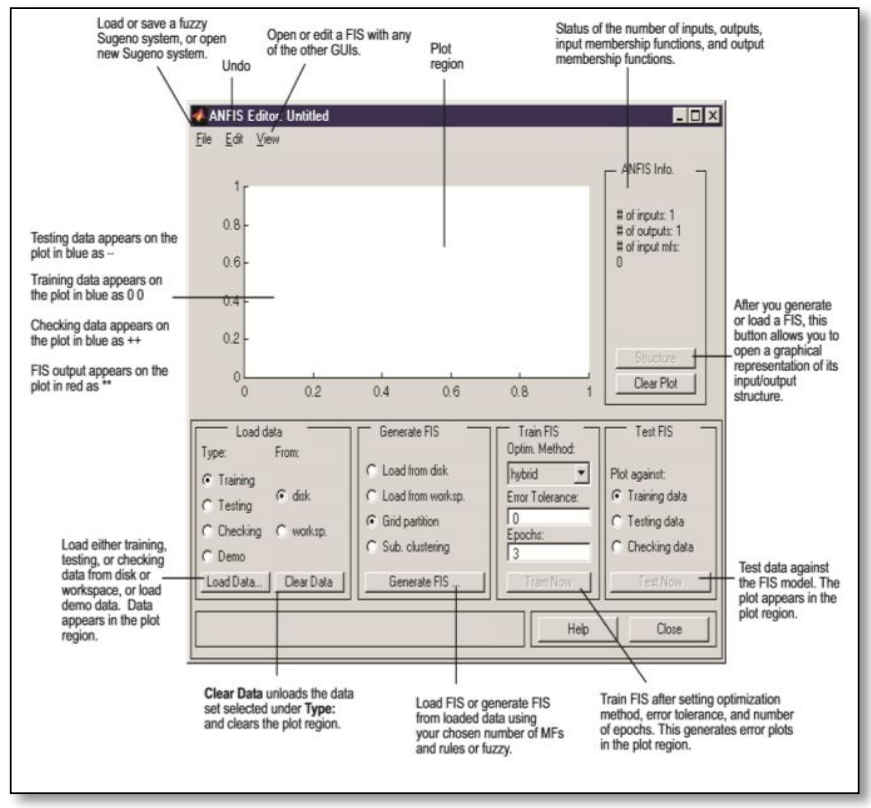

Fig.7 ANFIS Editor Windows.

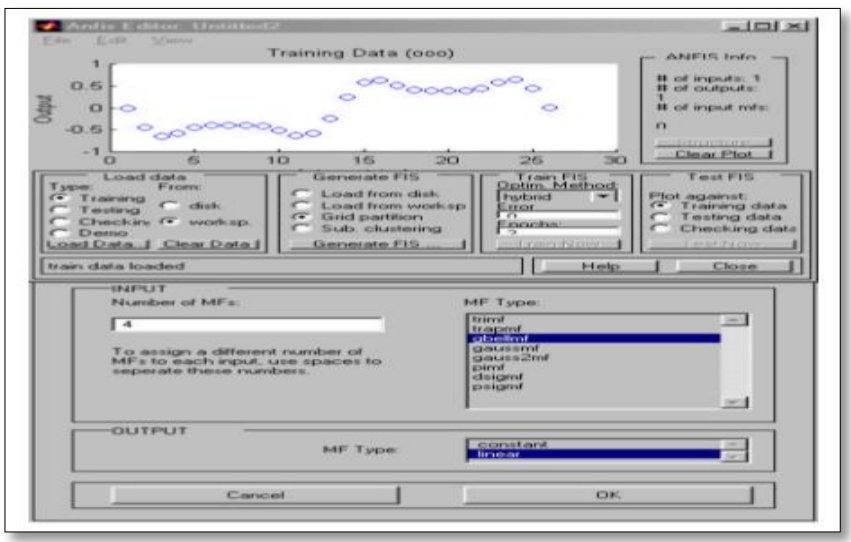

Fig.8 Load data and choose generate FIS. 


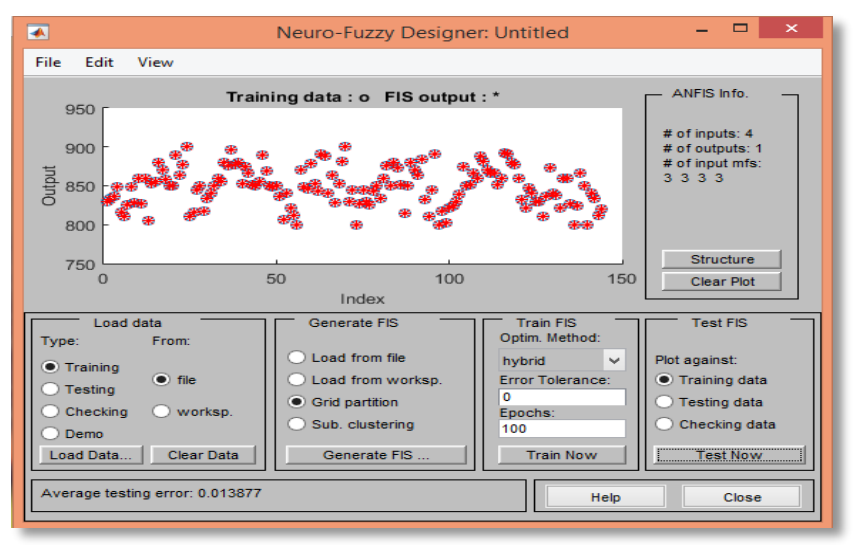

Fig.9 Training data

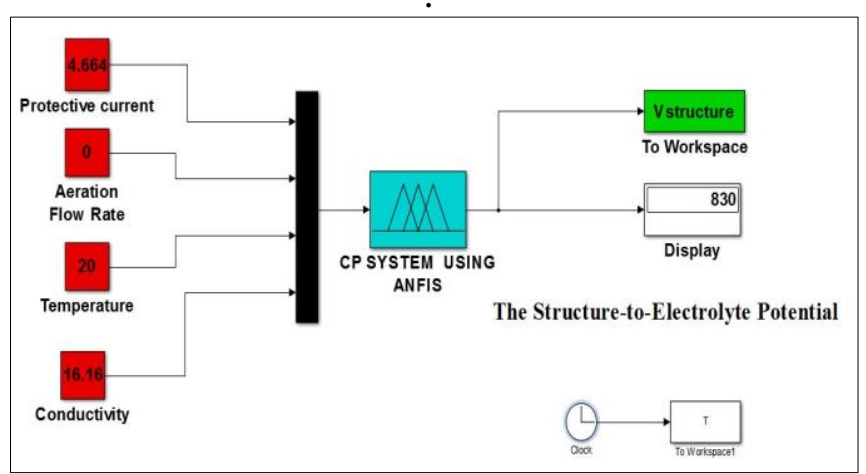

Fig.10 Simulink Model of ICCP System Using ANFIS.

\section{B) Control of ICCP System}

The control section consists of two techniques, the first technique represents the conventional PID controller, while the second represents the fuzzy controller.

\section{1) Conventional PID controller}

In this study, a PID controller was used to control the structure-to-electrolyte potential at a desired value (830) $\mathrm{mV}$. The PID controller is used to regulate the cathodic protection current during the changed of one of the three parameters such as temperature from $20^{\circ} \mathrm{C}$ to $25^{\circ} \mathrm{C}$ at time 10 second. Figure 11 shows the ICCP system model with PID controller. Figure 12 represents the response of the system under the PID controller, Fig(12-a) shows the cathodic protection current for the system that approximately increase from 1.4 to $3.2 \mathrm{~mA}$, while Fig(12-b) shows the output (the structure-to-electrolyte potential) in order to track reference voltage. Time response to reach stability situation approximately 6 seconds.

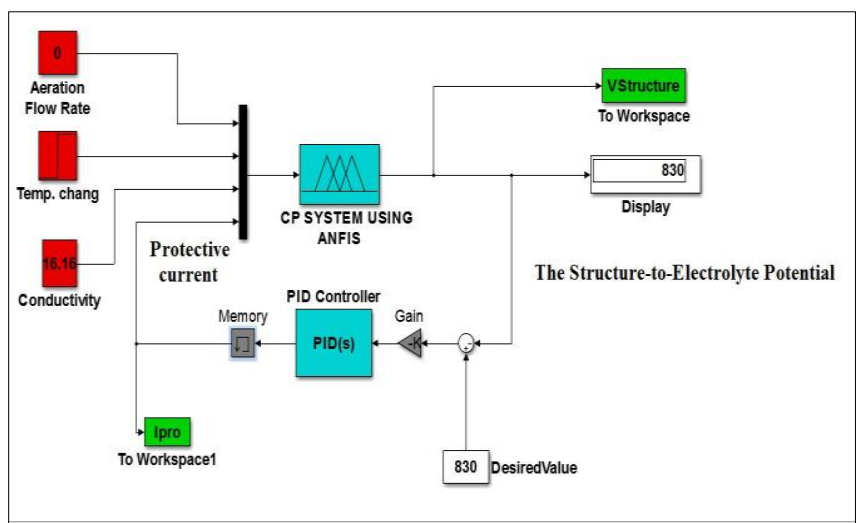

Fig.11 Simulink Model of PID Controller for ICCP System

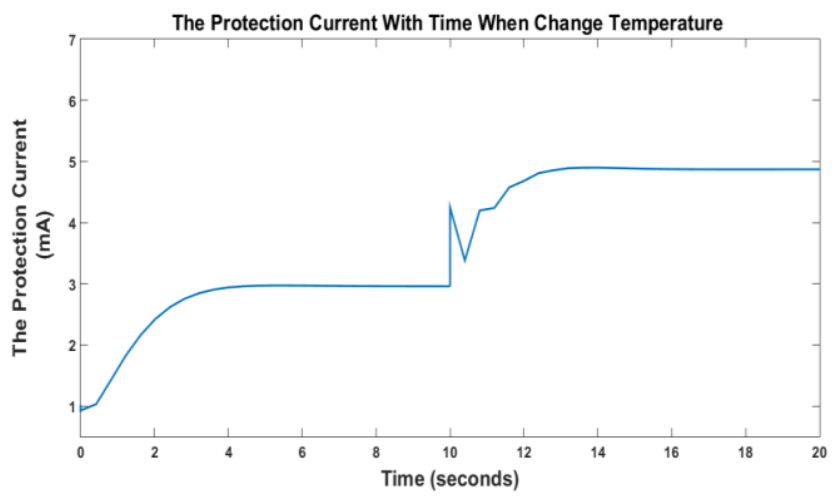

(a)

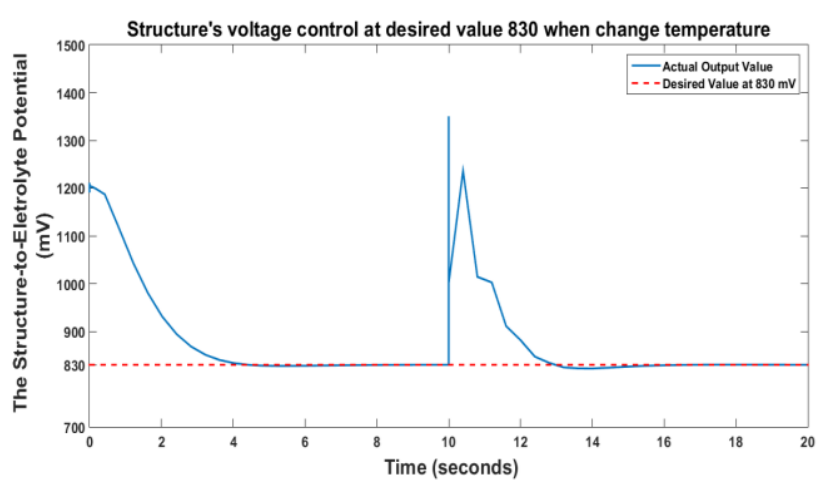

(b)

Fig.12 The response of the PID controller for ICCP system (a) Cathodic Protection Current, and (b) The Structure-to-Electrolyte potential.

\section{2) Fuzzy Logic Controller}

To overcome the limitations of the PID controller, different kinds of controllers were developed lately. One of them is a fuzzy logic controller (FLC). The inputs of fuzzy controller 
are the error (e) and integral of the error $(\sigma e)$. The output variable is the cathodic protection current ( $\mathrm{I}_{\text {pro }}$. Both the input variables and output variable have a set of possible linguistic values (NB, NS, $\mathrm{Z}, \mathrm{PS}, \mathrm{PB})$ shown in Fig.13 and Table 1 depicted the rules of FLC.

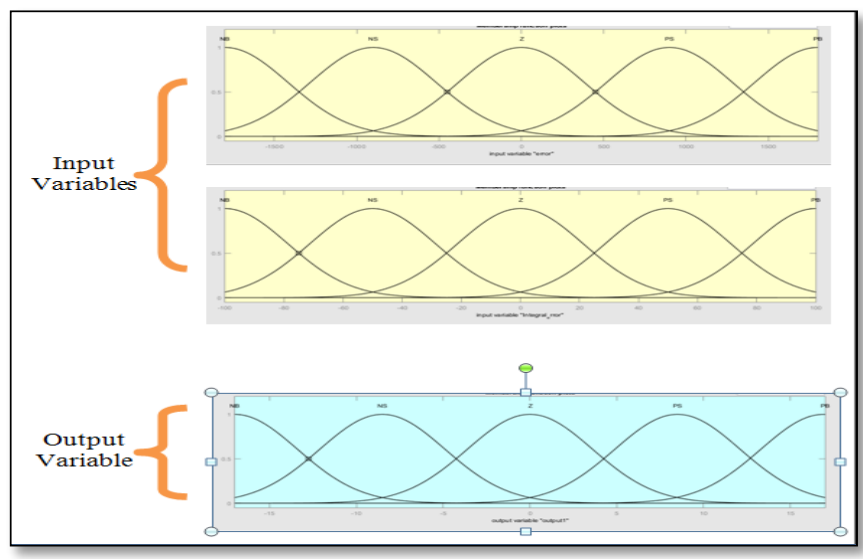

Fig.13 Membership Function for Inputs and Output of FLC.

Table 1. Control Rules for Fuzzy Controller.

\begin{tabular}{|c|c|c|c|c|c|}
\hline e & NB & NS & $Z$ & PS & PB \\
\hline NB & NB & NB & NB & NS & $Z$ \\
\hline NS & NB & NB & NS & $Z$ & PS \\
\hline$Z$ & NB & NS & $Z$ & PS & PB \\
\hline PS & NS & Z & PS & PB & PB \\
\hline PB & Z & PS & PB & PB & PB \\
\hline
\end{tabular}

Figure.14 shows the SIMULINK model of the fuzzy controller for ICCP system. Fig.15-a and b represent the response of cathodic protection current and the structure-to-electrolyte potential when the temperature change from $20^{\circ} \mathrm{C}$ to $25^{\circ} \mathrm{C}$ at time 20 second. And the desired output under control $830 \mathrm{mV}$. It can be seen that the time response to reach steady state less than one second, approximately equal to $0.7 \mathrm{sec}$.

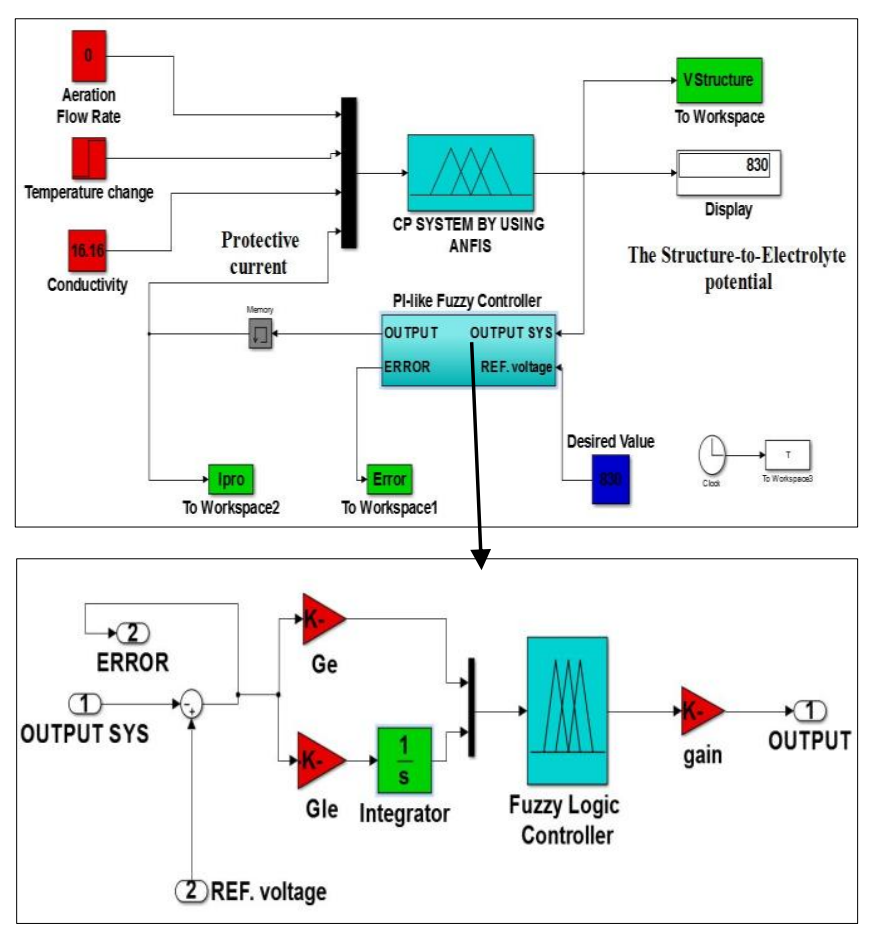

Fig 14. The SIMULINK model of the PI-like Fuzzy Controller for ICCP system.

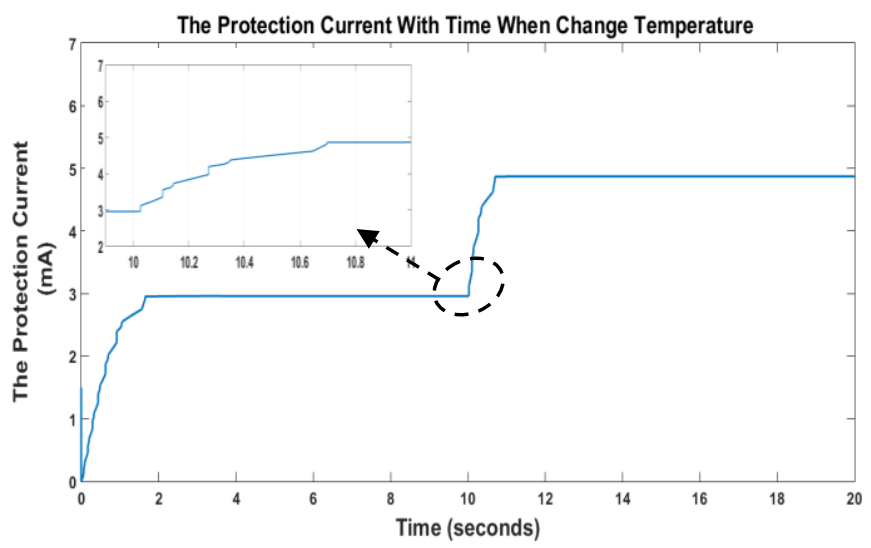

(a)

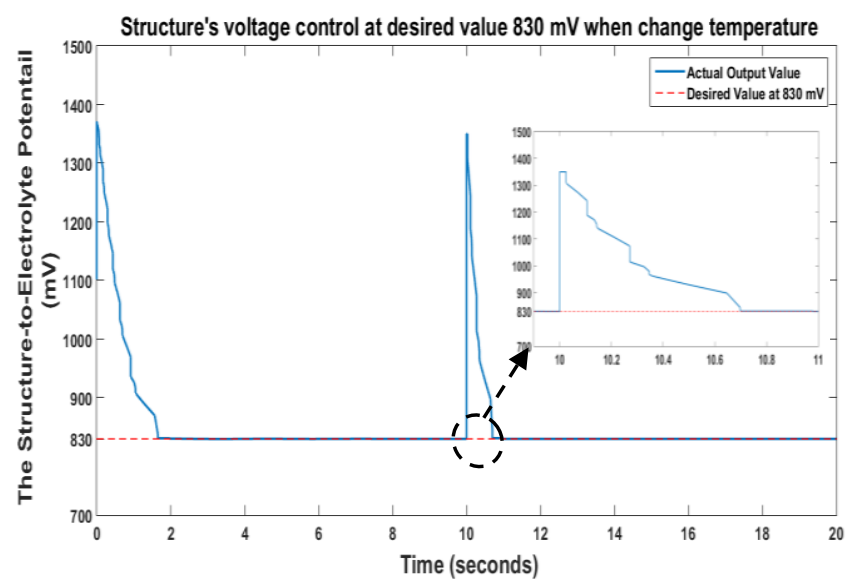

(b)

Fig.15 The response of Fuzzy Logic Controller for ICCP system (a) Cathodic Protection Current, and (b) The Structure-to-Electrolyte potential. 


\section{CONCLUSION}

In this paper, the parameters of an impressed current cathodic protection system have been identified using ANFIS technique and controlled by using a PID and fuzzy logic controller. From the experimental results, it can be concluded that the cathodic protection current increase for increasing the parameters such as temperature, conductivity and the aeration flow rate of the saltwater solution. And the cathodic protection current required for the old pipe greater than the new pipe segment for protection.

An ANFIS has proven to be efficient in identification model of ICCP system, and easy with MatLab Program to obtained equivalent model.

The PID controller can be applied to control ICCP system and quite easy to implement. But, it required very fine tuning of its parameters based on the desired value. Furthermore, it needed time response more than fuzzy controller to track reference voltage. For example, it took approximately $6 \mathrm{sec}$, but the fuzzy controller took less than one second, approximately equal to $(0.7$ sec) in the same changed of parameters. So that the fuzzy controller outperform the performance of the PID controller.

\section{REFERENCES}

[1] Philip A. Schweitzer, "Corrosion Engineering Handbook, Fundamentals of Metallic Corrosion Atmospheric and Media Corrosion of Metals ", 2nd edition, ISBN 978-084938243-7, 2007.

[2] Pier R. Roberge , "Hand book of corrosion engineers", ISBN 0-07-076516-2,2000.

[3] Peabody A.W.," Control Of Pipeline Corrosion", NACE International, ISBN 157590-092-0, 2001.

[4] Kareem M. Nagy, et. al., "Developed Software for Cathodic Protection of Storage Tanks", IEEE, 978-1-4673-0089-6/12, 2012.

[5] Balla, et. al., " System Identification Modelling and IMC Based PID Control Of Impressed Current Cathodic Protection Systems", International Journal on Smart Sensing and Intelligent Systems, Vol.6, No.5, December, 2013.
[6] Marwah S.Hashim, et. al., "Modeling and Control of Impressed Current Cathodic Protection (ICCP) System", Iraq Journal Electrical and Electronic Engineering, Vol.10, No.2, 2014.

[7] Sai Shankar B., et. al., "Solar Powered Corrosion Prevention in Iron Pipelines using Impressed Current Cathodic Protection", IEEE, 978-1-4799-4660-0/14, 2014.

[8] Xiaohua Wang, et. al., "Design and Implementation of the Remote Control of ICCP Systems", IEEE, 978-14799-3708-0/14, 2014.

[9] Mansi. R., "Cathodic Protection of Impressed Current method for carbon steel in $3.5 \% \mathrm{NaCl}$ solution", MSc. thesis, University of Technology, Chemical Engineering, 2007. 